\title{
1972-2012: Um registo poético de quatro décadas
}

Ricardo Marques

FCSH/Universidade Nova de Lisboa

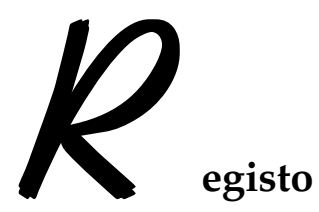

s. m.

1. Qualquer livro público ou particular onde se inscrevem factos ou actos que se querem conservar arquivados.

2. Acto de registar: v.tr.

3. Tomar nota, assentar o dito (por escrito ou na memória) para não olvidá-lo ou para servir de argumento quando necessário for.

A Noção de Poema

O Pavão Sonoro

Crítica Doméstica dos Paralelepípedos As Inumeráveis Águas

OMecanismoRomânticodaFragmentação

Nos Braços da Exígua Luz

OCorte na Ênfase

O Voo de Igitur num Copo de Dados

A Partilha Dos Mitos

Lira de Líquen

A Condescendência do Ser

Enumeração de Sombras

As Regras da Perspectiva

Um Canto na Espessura do Tempo

Meditação sobre Ruínas
O Movimento do Mundo

A Fonte da Vida

Teoria Geral do Sentimento

Rimas e Contas

Jeu de reflets/Jogo de reflexos

Cartografia de Emoções

Pedro, lembrando Inês

O Estado dos Campos

Geometria variável

Geografia do Caos

As Coisas Mais Simples

A Matéria do Poema

O Breve Sentimento do Eterno

Guia de Conceitos Básicos

Fórmulas de uma luz inexplicável 
"Registo Manual"1

Comecei por escrever com a caneta de tinta permanente, que sujava os dedos; passei para esferográficas que riscavam o papel; troquei-as por uma sólida triumph de teclado hcesar, que fazia doer o dedo com que a martelava; e passei daí para o azert de uma olivetti de batida mais leve, para que o poema se fosse tornando mais pesado, com o virar do rolo a cada cesura; e o verso tornou-se um intervalo entre dois ruídos, com o seu silêncio pontuado pelo bater da tecla no papel. Por fim, o computador trouxe-me ao qwertz; mas quase voltei

a ouvir o riscar da caneta no papel, ao olhar para o ecrã e descobrir o vermelho a sublinhar erros nascidos da pressa do poema, que tinha de corrigir na rasura abstracta do ecrã.

Com o tempo, foram mudando as tintas, as canetas, as máquinas; e só o poema continuou a ser o mesmo, feito à medida dos dedos que aprenderam a passar da tinta ao teclado, do hcesar ao qwertz, passando pelo azert, e do verso ao verso, nos versos e reversos do papel.

\section{II}

“Não me costumo reler, e se há temas recorrentes deixo ao crítico o trabalho de os encontrar. [...] vejo a minha poesia como um longo poema que terá começado entre meados e fins da

${ }^{1}$ JÚDICE, 2008, p. 100. 
década de 1960, e ainda não acabou. Quanto a mudanças, não há nada pior do que pretender mudar.

Escrevo, reescrevo, rasuro: é este o meu trabalho."

Nuno Júdice, $2012^{2}$

Escrita ao longo das últimas quatro décadas, o "longo poema" de Nuno Júdice foi-se tornando numa das mais conhecidas e consagradas poéticas contemporâneas, dentro e fora de Portugal. Uma teoria anti-teoria, como sempre é qualquer teoria feita em poema, ou, numa palavra, uma poesia que é Jogo (e que também é metamorfose do próprio "jogo de fazer versos" - Gil de Biedma), o que, para citar Roland Barthes, numa obra que por sua vez é um jogo autobiográfico - Roland Barthes par Roland Barthes - se plasma da seguinte forma: "O verdadeiro jogo não consiste em mascarar o assunto, mas sim em mascarar o próprio jogo". É esta a arte e o método da poesia de Nuno Júdice.

Para começar a falar disso, quisemos lembrar, em primeiro lugar, os marcos desse percurso, um por um. Se analisarmos todos os elementos que compõem os títulos das suas obras, sobretudo as mais recentes, e atentar na ironia por detrás deles, descobrimos inúmeras combinações contrastivas na forma de perceber o que é essa coisa que denominamos poema. É que qualquer um dos seus títulos pode ser, por si só, uma forma de definir o que é o fenómeno poético. Sem querer ser exaustivo, Júdice propõe-nos uma "noção" (1972), um "mecanismo" (1975), "regras" (1990), uma "teoria" (1999), uma "cartografia" (2002), um "guia" (2010), chegando às "fórmulas" deste ano. Esse princípio normativo, porém, está sempre ligado a princípios

2 De uma entrevista efetuada ao autor, presente in www.poemsfromtheportuguese.org. Acedido a 10 de Novembro de 2012. 
mais indefiníveis e subjectivos, ou não estivéssemos a falar de poemas, do fenómeno poético - "fragmentação" (1975), "perspectiva" (1990), "sentimento" (1999), "emoções" (2002), "variável" (2005), "inexplicável" (2012).

Escrevo, reescrevo, rasuro.

\section{III}

Gostaria agora de deixar algumas pistas de leitura do texto poético de Nuno Júdice. Começo assim por dizer o óbvio: a identidade de um poeta, bem como de um determinado movimento ou corrente literária, é sempre de difícil, senão impossível, determinação. Etimologicamente, a palavra aponta para a continuidade e consistência de características definidas que Erik Erikson, um dos mais conceituados psicólogos da identidade do século XX, amplamente estudou. ${ }^{3}$ No entanto, e no caso particular que aqui temos, nenhuma perspectiva sobre a identidade deste poeta poderia estar completa sem uma reflexão crítica sobre o objecto que a determina - isto é, a sua obra. Em segundo lugar, numa reflexão deste tipo teremos de lembrar conceitos limítrofes - a tradição e a genealogia, bem como a influência e a memória - que, problematizados, ajudam, de uma forma mais coesa, a perceber onde esta poesia se situa e o que a define.

Uma identidade tem a ver com a inserção numa tradição que a funda (veja-se a entrevista deste dossier temático), seja por rejeição declarada, seja por acolhimento deliberado. Esta atitude, por sua vez, permite estabelecer uma genealogia de autores, facto a que Júdice não é alheio:

\footnotetext{
3 "[The] sense of identity provides the ability to experience one's self as something that has continuity and sameness, and to act accordingly." ERIKSON, 1963, p. 42.
} 
Se a lei da gravidade é o que puxa os corpos para o centro da terra, o que é que nos puxa para o centro do poema? [...] Essa força, para mim, tem um nome: imagem. E aqui encontro o que talvez seja a minha tradição: o "ut pictura poesis" da Arte Poética de Horácio, a frase que deixa de se repetir na minha cabeça e que me obriga a nunca deixar que um poema caia no simples formalismo. ${ }^{4}$

O conceito de imagem é fundamental na abordagem da poética deste autor. A formulação horaciana de "ut pictura poesis" a que Júdice se junta influencia muitos dos seus poemas onde a imagem que descreve, isto é, a apreensão mental de uma realidade sensível, se encontra nas formas mais variadas, desde outras obras de arte (e aqui podemos dizer que a este autor em particular interessam muito as artes visuais, sobretudo a pintura e a fotografia) até às coisas banais do quotidiano. $^{5}$

A poesia de Nuno Júdice é, de forma geral, uma poesia contrastiva, de espelhos poliédricos, pondo a funcionar essa dialéctica a diversos níveis. Em primeiro lugar, na forma do poema há uma variação entre uma estrutura discursiva e uma estrutura contida e depurada, muitas vezes apenas numa única estrofe. $\mathrm{O}$ estilo narrativo verifica-se desde os primeiros livros, mas é nos últimos que a convivência entre estes dois paradigmas se verifica mais. Ainda no que toca à estruturação externa do poema, verifica-se um recurso tanto a formas tradicionais (a quadra, por exemplo, bem como outras da literatura tradicional portuguesa) como a formas fixas, com particular destaque para

${ }^{4}$ JÚDICE, 1999, p. 251.

${ }^{5}$ Um dos livros mais interessantes e menos estudados, onde não só o diálogo ecfrástico está presente, mas uma perspectiva mais engagée e política sobre os assuntos do quotidiano é, sem dúvida, Geografia do Caos (2005). 
o soneto. ${ }^{6}$ Em ambos os casos regista-se, muitas vezes, o aproveitamento simples de formas fixas, como a ode e a elegia, convivendo de perto com a subversão de outras, com destaque para o soneto e o epigrama.

Passemos a um exemplo. Escrever, reescrever, rasurar é o que também está presente em "História de Arte", 7 um dos poemas que, se me permitem, considero central no cânone judiciano. $\mathrm{O}$ texto em questão, verdadeiramente desafiador e interdisciplinar, tem a particularidade de ser um poema sobre um aspecto particular da história da arte portuguesa, mas que Júdice entretece com alusões à Literatura (na figura de Camões, sobretudo).

É de salientar, em primeiro lugar, a dedicatória do poema, uma vez que aqui encontramos o primeiro cruzamento interdisciplinar do poema. Ao dedicá-lo a Victor Manuel Aguiar e Silva, colocando-o em epígrafe, provoca Júdice desde logo a estranheza no leitor que conhece o teórico, por ser um poema com um título filiado num tipo de arte diferente daquela onde este professor se celebrizou (a Literatura). Assim, com estes dois dados, vamos ler uma primeira parte do poema:

Para Victor Manuel de Aguiar e Silva

Quando sequeira pintou "a morte de camões", estava longe de imaginar que os seus restos teriam destino idêntico aos do poeta. O tibre, inundando a igreja onde o enterraram, devastou sepulturas e confundiu todos os

\footnotetext{
${ }^{6}$ A propósito desta forma fixa, o poeta reflecte sobre o processo de escrita de sonetos num intróito a um dos últimos livros de poesia, O Breve Sentimento do Efémero (2008), referindo que segue um modelo académico e estabelecido, que pretende depois imitar.

7 JÚDICE, 2005, p. 42-43.
} 
ossos, que foram juntos em comum sarcófago. O que ele também não soube é que essas cinzas se iriam juntar às do seu quadro, queimado pela multidão em revolta, no incêndio das tulherias.

Sendo sobre um quadro alusivo a Camões, cuja vida depois Júdice relaciona com o pintor romântico Domingos Sequeira, podemos avançar com a hipótese de este ser um poema encomiástico para com o camonista Aguiar eSilva. Posto isto, eapós avançar com este facto histórico, Júdice prossegue o poema com o início da narração imaginada, e que parte deste mesmo facto:

Tudo isto estava longe do seu espírito quando ouviu o pintor gerard dizer-lhe que reconhecia nele a mão de um verdadeiro artista. Sequeira apreciou o elogio; e, em carta ao irmão, pediu-lhe o favor de uma encomenda de duas caixas de laranjas, das melhores, e de pele fina e das mais doces, e também de tangerinas, para obsequiar o amigo, a quem ele falara das uvas de lisboa, que eram melhores do que as francesas. Na conversa, gérard dissera-lhe que o melhor modo de as mandar vir seria em bagos soltos, envolvidos em algodão; e é provável que laranjas, tangerinas, e uvas tenham chegado, de lisboa, à mesa do pintor gérard, para que ele saboreasse a sua pele fina, e as mais doces, junto de sequeira, a quem a "morte de camões" serviu de motivo. [... $]^{8}$

Nesta segunda parte temos a inclusão de um novo elemento na história, o pintor romântico François Gérard, que conviveu com Sequeira quando este se exilou em França no decurso da "Vilafrancada". O próprio narrador do poema remete para a esfera do "provável" que certos eventos se tenham passado (vv. 17-18). O que nos interessa salientar aqui,

${ }^{8}$ JÚDICE, 2005, p. 42-43. 
analisando esta parte em cotejo com a primeira, é a forma discursiva e fluída como Júdice estrutura o seu texto poético, numa segunda parte que se torna uma narrativa decorrente da primeira. Por um lado, é de notar os vários elementos que revelam uma fusão do modo lírico com o narrativo, nomeadamente nos elementos de ligação entre frases (" Tudo isto estava [...] quando", por exemplo), tornando a acção mais encadeada. Por outro lado, note-se a estrutura em espelho desta segunda parte (esta parte acaba e começa com a referência a "sequeira", e repete no princípio e no fim a mesma forma de descrever as frutas), bem como a marca da sinestesia na descrição das frutas.

[...] No entanto, se ele soubesse que os seus ossos teriam o mesmo fim que as cinzas do poeta, talvez não tivesse desafiado o destino; a não ser que confiasse nas ninfas do tibre, como o poeta acreditara nas tágides. Um inverno, porém, o tibre passou por cima das suas ninfas, tal como o tejo afogou as tágides; e se inundações e terramotos os aproximaram depois da morte, também no exílio partilharam a mesma saudade de lisboa, embora sequeira se lembrasse de uvas, laranjas e tangerinas, e camões, das mulheres, as de pele fina, e das mais doces.

Neste excerto seguinte, há um claro retomar do facto histórico dado logo de início, sobre a coincidência das duas mortes em circunstâncias anacronicamente semelhantes. Júdice continua a narrativa dentro do poema ("no entanto", "porém"), e a estrutura em espelho. O final é concebido no registo irónico tipicamente judiciano, justapondo as duas vidas de Camões e Sequeira sobre as quais o poema assenta, e cujo referente é uma obra de arte que os une. Se, por um lado, a alusão a Camões, através das Tágides, é ligada a um facto biográfico de Sequeira, que acabou os seus dias em Itália, onde passa o rio Tibre, o tema do exílio vem à tona nos últimos versos, bem como as frutas que anteriormente se descreveram, numa descrição ambígua que retoma a sinestesia começada atrás e lhe dá contornos 
personificantes ("a mesma saudade de lisboa/embora sequeira se lembrasse de uvas, laranjas e tangerinas / e camões, das mulheres, as de pele fina, e das mais doces").

Em suma, o que Júdice orquestra aqui é a escrita sobre um aspecto histórico particular, que depois desenvolve numa ficção, tudo num jogo a três tempos que relaciona três vidas de três artistas diferentes. Escolhi então este poema para ilustrar este "registo" por várias razões que já se adivinham: é um bom exemplo de como Júdice funde o real concreto com uma história imaginada, misturando no mesmo passo um poema com uma narrativa cronologicamente irregular. Neste sentido, é igualmente de salientar neste poema a colagem, que em muitos poemas judicianos acontece, de elementos referentes a uma determinada esfera estética, e de outros referentes a outras, mostrando uma rede intertextual que não se formula apenas nos moldes de um sistema, mas fundindo vários ao mesmo tempo. Deste modo, o poema acaba sendo uma teia de ligações para diversos domínios do saber, que ali se condensam.

Assim, sendo este poema uma história, é também ele a verdadeira "história de arte", por sinédoque, que o título manifesta. É a história, no sentido de ficcionalização, das várias histórias paralelas que não ficam registadas na história da história de arte, na história da estética: Escrever, reescrever, rasurar.

\section{IV}

Permito-me agora uma surpresa final ao leitor - um inédito. ${ }^{9}$ Não é que nos falte material - a obra deste poeta é muito extensa, e certamente haveria muitos poemas já publicados "que poderiam ser paradigmáticos deste percurso", como o fiz atrás. Se o escolho fazer é porque subscrevo o que o

${ }^{9}$ Cedido gentilmente pelo autor, a quem aproveitamos para agradecer. 
próprio autor diz no seu $A B C$ da Crítica - "o lugar do crítico é sempre o do leitor" - e foi esse sempre o meu papel primeiro, é este o meu papel aqui. Não poderia terminar este percurso sem retirar da arca daquilo que (ainda) não foi publicado, um texto, escolhido subjectivamente por mim, como leitor, e portanto servindo um propósito que neste texto faltava - o de elucidar, mostrando (show and tell) o tal "registo manual" que faz o poema das últimas quatro décadas continuar

a ser o mesmo, feito à medida dos dedos que aprenderam a passar da tinta ao teclado, do hcesar ao qwertz, passando pelo azert, e do verso ao verso, nos versos e reversos do papel.

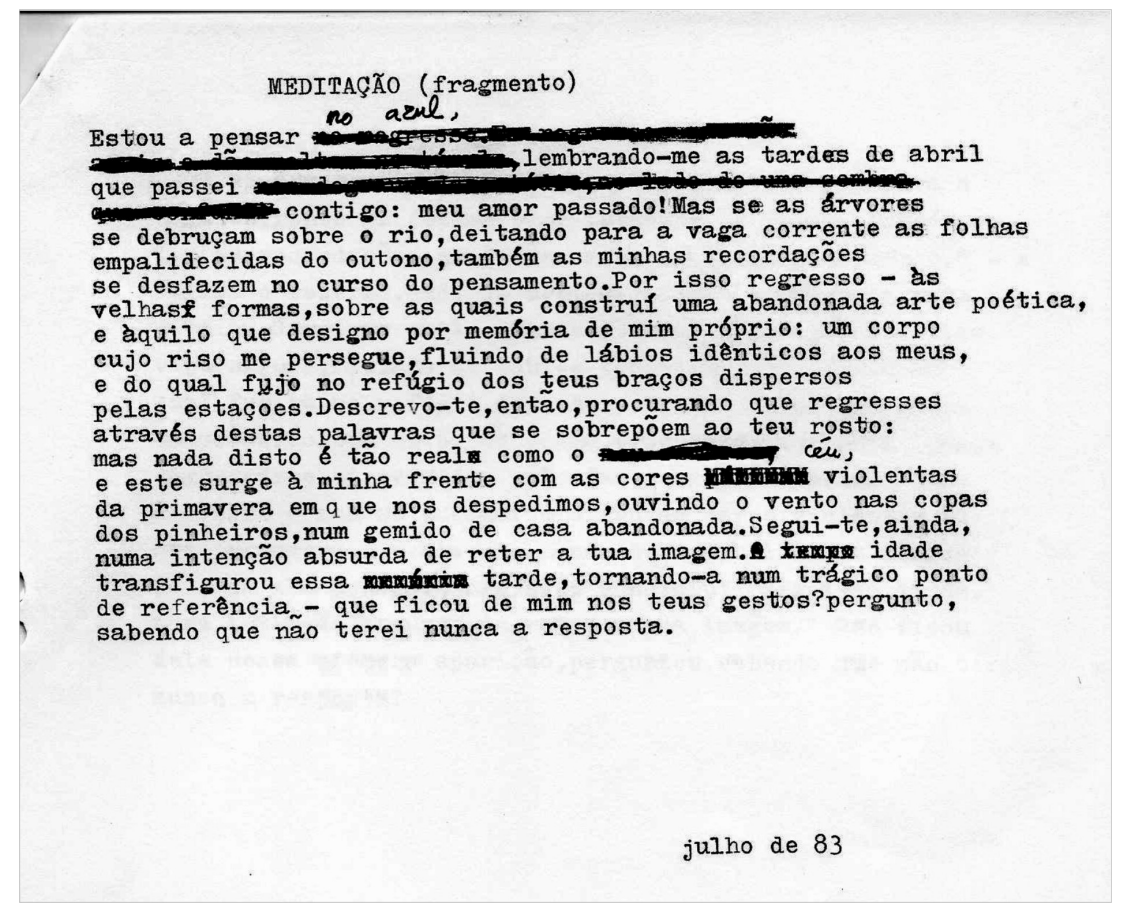


O poema em questão tem por título "Meditação(fragmento)", e está datado de Julho de 1983, escrito em lugar desconhecido:

Aprendemos na obra judiciana que um poema é uma mesma reflexão sobre si próprio, a um dado momento em que esse mesmo momento que faz escrever já passou. É o que com ele diz T.S. Eliot, no início dos seus Quatro Quartetos: “Time present and time past/ Are both perhaps present in time future/ And time future contained in time past./ If all time is eternally present/ / All time is unredeemable."10

O sujeito poético medita assim ("estou a pensar"), num fragmento de tempo sobre um amor antigo, mas por analogia sobre o tempo passado desse amor que passou e, por conseguinte sobre o tempo em que está, recorrendo à "memória de mim próprio: um corpo/cujo riso me persegue". O poema, esse outro corpo de "velhas formas", "uma abandonada arte poética", vai tentar "sobrepôr-se ao teu rosto", "numa intenção absurda de reter a tua imagem".

Retoricamente, o texto envolve-se num silogismo em espiral, com o verso longo advindo do seu interesse pelos modernistas, mas igualmente com o topos clássico de um mestre seu de sempre, Camões ("as tardes [...] que passei contigo: meu amor passado"), ${ }_{11}^{11}$ casando os dois numa manipulação estética das palavras (emblema da sua identidade), e terminando com a mesma impossibilidade que começa - a de resgatar ao tempo passado, através do poema, aquilo que só o real ("o céu", "o azul") lhe pode dar.

É nisto que Júdice continua a ser mestre sem par no panorama da poesia portuguesa actual: retira do contexto,

${ }^{10}$ Cf http://www.coldbacon.com/poems/fq.html - consultado a 10 de Novembro de 2012.

${ }^{11}$ Vejamos, a título de comparação, o soneto camoniano que começa com o verso "Lembranças, que lembrais meu bem passado". 
analisa, decompondo, complexificando, para de novo dar ao leitor, sempre com as palavras no seu lugar certo, sempre com uma musicalidade interna, sem necessidade de rima, e, também por tudo isso, com uma linguagem acessível a todos. Assim vai formando um registo, assim vai forjando um caminho a cada passo.

Voltando aos seus títulos, e pegando no primeiro e no último, há entre $A$ Noção de Poema (1972) e Fórmulas de uma luz inexplicável (2012), por exemplo, uma diferenciação que não será, talvez, muito grande no pressuposto de que faz escrever ambos os livros. Dito por outras palavras, a afinidade de objectivos entre escrever sobre "a noção" e "a fórmula", é concorrente e concomitante no caso deste poeta. No entanto, a inicial invectiva do primeiro livro é diametralmente diferente da técnica empregada no livro de 2012. No livro de 1972 temos o poema enquanto objectivo último de reflexão poética no sentido de se acercar, pelos próprios poemas que preenchem $\mathrm{o}$ volume, do que significa poesia. Já no livro de 2012, a matéria do poema é declaradamente a sua "fórmula", isto é, encarada como a própria noção de poema que o primeiro livro questiona. ${ }^{12}$

Quarenta anos depois, esta é assim seguramente uma metapoética sólida e essencial no panorama da literatura portuguesa contemporânea, uma poesia que, ao reflectir activamente sobre si, soube renovar caminhos já trilhados e reinventar-se, explorando o seu próprio trilho, o seu próprio "registo" poético.

${ }^{12}$ Não podemos perder de vista a epígrafe inicial deste livro, do poeta Rui Diniz, em que se defende que qualquer significado do que é poesia apenas vale pela própria palavra poética, pelo poema e sua leitura. Como diz Diniz, "[...] é ainda praxis a sua teorização." JÚDICE, 2000, p. 55. 


\section{CODA}

\section{PENÉLOPE}

Escrevo, reescrevo, rasuro.

Enquanto isso, espero pelo grande poeta da minha alma. Começar de novo é sempre difícil, porque se recomeço é sinal de ausência, não de calma, nunca de chegada.

Desfaço porém com o mesmo afinco de quem tece a sua mortalha - quando ele chegar, e eu velha de corpo, cansada, confundirme-ei com a morte, serei o tear do seu suporte, a cama onde por fim me deito com o mais apurado poema no punho.

Recomeçar é sempre difícil porque nunca será começar de novo. E no fim, no fundo, fica sempre tanto por dizer.

E era isto que ao invés vos poderia, e lhe poderia, ter dito sobre ele. 


\section{Referências}

AA.VV: Românica - Revista de Literatura do Dept. de Literaturas Românicas - FLUL, n. 7, Lisboa, 1999.

ERIKSON, Erik. Childhood and Society. Norton; NY, Second Edition, Revised and Enlarged edition, 1963.

JÚDICE, Nuno. Fórmulas de uma luz inexplicável. Lisboa: Publicações Dom Quixote, 2012.

JÚDICE, Nuno. Geometria Variável. Lisboa: Publicações Dom Quixote, 2005.

JÚDICE, Nuno. A Matéria do Poema. Lisboa: Publicações Dom Quixote, 2008.

JÚDICE, Nuno. Poesia Reunida. Lisboa: Publicações Dom Quixote, 2000. <http:/ / www.coldbacon.com/poems / fq.html> - consultado a 10 de Novembro de 2012.

<http:/ / www.poemsfromtheportuguese.org.> - consultado a 10 de Novembro de 2012. 


\section{Resumo}

Nuno Júdice é actualmente um dos mais interessantes poetas portugueses. Amplamente traduzido e reconhecido com diversos prémios (nacionais e internacionais), também é professor universitário e director de uma das mais prestigiadas revistas literárias do seu país.

Sendo 2012 o ano em que comemora 40 anos sobre o seu primeiro livro, A Noção de Poema, vimos assim propor uma reflexão sobre os seus temas enquanto poeta, usando, sempre que possível, as suas próprias palavras, e incluindo um poema nunca antes publicado.

Esperamos assim dar a entender melhor onde este extenso poema que Júdice vem escrevendo há já quatro décadas se situa, em especial no dealbar deste século.

\section{Abstract}

Nuno Judice is one of the most challenging Portuguese poets alive. Widely translated and recognized with numerous awards (national and international), he is also a University professor and Director of one of the most prestigious literary magazines in his country.

Since 2012 is the year that marks the $40^{\text {th }}$ anniversary of his first book of poems, A Noção de Poema, we therefore propose a reflection on his major themes as a poet, exemplifying his poetical path, whenever possible, with his own words. We will include an unpublished poem in our reflection.

We hope to provide a clearer understanding on where we can position this poet after four decades of intensive poetry writing, especially at the dawn of this century. 